\title{
A Community Pharmacist-led Smoking Cessation Intervention Using a Smartphone App (PharmQuit): A Randomized Controlled Trial
}

Narong Asayut

Mahasarakham University

Phayom Sookaneknun Olson ( $\square$ phayom.s@msu.ac.th )

Mahasarakham University https://orcid.org/0000-0002-3618-3115

Juntip Kanjanasilp

Mahasarakham University

Preut Thanarat

Mahasarakham University

Bhattaraporn Senkraigul

Mahasarakham University

Chuthathip Sittisarn

Mahasarakham University

Suratsawatee Suksawat

Mahasarakham University

\section{Research article}

Keywords: PharmQuit, smartphone app, smoking cessation, community pharmacist, Thailand, app, phone app

Posted Date: November 18th, 2020

DOI: https://doi.org/10.21203/rs.3.rs-108689/v1

License: (c) (i) This work is licensed under a Creative Commons Attribution 4.0 International License. Read Full License

Version of Record: A version of this preprint was published at PLOS ONE on March 29th, 2022. See the published version at https://doi.org/10.1371/journal.pone.0265483. 


\section{Abstract}

Background: WHO supports the harnessing of mobile technologies to improve access to smoking cessation services. PharmQuit, a smartphone app, was developed to support smoking cessation efforts by pharmacists taking into consideration the design of the app according to the needs of smokers. This study evaluated the effectiveness of smoking cessation services conducted by community pharmacists using PharmQuit compared with standard care.

Methods: An open-label prospective, randomized, controlled trial was conducted. Stratified random sampling by sex, age, and nicotine addiction was used to allocate participants to either the intervention group or control group. Eligible participants were smokers 18 years old or older who smoked at least one cigarette daily for a month, were ready to quit, willing to participate, and had a smartphone. The study was performed at seven community pharmacies situated in three provinces in Thailand. In the intervention group, participants received smoking cessation services by community pharmacists using PharmQuit. The control group received standard care delivered by community pharmacists. Both groups were scheduled follow-ups at day $7,14,30,60,120$, and 180 . The primary outcomes were quit rate and number of cigarettes smoked per day. Secondary outcomes were exhaled carbon monoxide levels, adherence rate to the program, and satisfaction with PharmQuit. Analysis using the intent-to-treat principle was carried out.

Results: A total of 156 smokers were randomly assigned to either the intervention $(n=78)$ or control $(n=78)$ group. Smoking cessation rates and the number of cigarettes smoked per day were significantly better over the follow-up visits in both groups $(p<0.05)$. However, there were no statistically significant differences between the two groups. Adherence rate to the smoking cessation program was higher in the intervention group than the control group (74 days vs 60 days, $p>0.05$ ). Relapse rate was found to be lower in the intervention group as compared to the control group (28.6\% vs $71.4 \%)$.

Conclusions: The results showed obvious benefits of the community pharmacist's contribution in helping smokers quit smoking. PharmQuit was not better than just pharmacist's counselling but it might help to obtain better adherence to smoking cessation programs, and have less likelihood of relapse.

Trial registration: Thai Clinical Trials Registry: TCTR20200925004. Registration date September 25, 2020 - Retrospectively registered, http://www.clinicaltrials.in.th/index.php? tp=regtrials\&menu=trialsearch\&smenu=fulltext\&task=search\&task2=view1\&id=6841

\section{Background}

Tobacco smoking is a major cause of premature death worldwide [1]. Tobacco prematurely kills up to half of its users. In 2017, smoking was the second leading risk globally (following hypertension) for premature death and disability ranked by disability adjusted life years (DALYs) [2]. WHO has a global action plan to reduce the prevalence of tobacco use in persons aged 15 years and older by $30 \%$ by the year 2025 [3]. In Thailand the smoking prevalence among the general population in 2010 was 42\%. The 
benchmark of a $30 \%$ relative reduction requires that the smoking prevalence in Thailand be reduced to $30 \%$ by 2025 . With the combination of tobacco control policies and rate of smoking cessation, the relative prevalence is predicted to be $34 \%$ in 2025 which, however, is still higher than the WHO target [4]. Increased efforts to control tobacco use are essential for reducing the burden of non-communicable diseases in Thailand [4].

Counselling for smoking cessation is effective in helping smokers quit. Lancaster and Stead showed that different models of counselling provided benefits to participants [5]. Nicotine replacement therapy (NRT) increased the rate of quitting by $50-60 \%$ for people who made an attempt to quit-regardless of setting [6]. A combination of pharmacotherapy plus high-intensity behavioral treatment is better than the highintensity behavioral treatment alone [7]. Health professionals, such as pharmacists, are in a unique position to help smokers quit. Several systematic reviews have shown that pharmacist-led interventions result in better abstinence rates in smokers [8-11], and may also be cost-effective [11-12]. However, pharmacy counselling programme still has a high drop-out rate [13].

Although various mobile apps are available to help smokers quit, studies have shown that only two out of 50 apps were accompanied with scientific and professional support [14] and most apps were not customized to the users' needs [15]. The aims of this study were to help smokers to adhere to a smoking cessation program, in which pharmacists assisted and provided information and support for smokers. Developed for iOS and android phones, PharmQuit aims to help "ready-to-quit" smokers with the help of community pharmacists. PharmQuit was developed using the five user experience framework with perspectives from smokers and pharmacists and was designed to deliver easy access to users. PharmQuit sends encouraging messages to the users' phone every day to remind them to keep a daily record of smoking and encourage them to be abstinent. It gives them information about cravings and adverse drug reactions from medications. Users can see clinical data screened by their pharmacists in PharmQuit and they are also able to send messages directly to their pharmacists through Line@ in PharmQuit. They can see the status of how well they are doing in the program depicted by an avatar. They also can share their status with others in the PharmQuit community.

Current evidence shows benefits of mobile phone-based smoking cessation interventions on long-term outcomes [16]. A few studies of smoking cessation apps have been conducted in community pharmacies and evaluated for short term (8 weeks) outcomes [17-18].

\section{Aim Of The Study}

To evaluate the effectiveness of pharmacist-led quit-smoking smartphone app, PharmQuit, on abstinence rate, number of cigarettes smoked per day, carbon monoxide level, adherence to the smoking cessation program, and satisfaction with the app.

\section{Method}




\section{Design}

This study was an open-label randomized trial with a control group. Stratified random sampling was used for both the control and intervention groups and was based on age, gender and nicotine dependence. This study adheres to CONSORT guideline [19] and includes a completed CONSORT checklist as additional file 1. Cash compensation of 1.50 US dollars per visit were given to each smoker and 16.7 US dollars per smoker was given to each community pharmacist who worked with a smoker.

The satisfaction questionnaire for PharmQuit was specifically developed for this study using the 5-Likert scale (additional file 2). The Cronbach's alpha was 0.923 . User's experience theory was used as a framework for developing the questionnaire. Validity was verified by 3 experts in questionnaire development and research. There were 21 questions in 5 dimensions: objectives in quitting smoking, scope of application, format and interaction, design, and appearance. Online and paper-based questionnaires were administered to participants in the intervention group.

\section{Participants}

The recruitment was through invitation by pharmacy students, community pharmacists, health care providers, and health care volunteers. Seven community pharmacies in 3 provinces participated in this study. The recruitment period was from July 30, 2017 to August 28, 2018. The study completed in January 2019.

Eligible participants were smokers who were (1) aged 18 years or older, (2) smoking at least one cigarette per day for a month or more, (3) ready to quit smoking or in the preparation stage, (4) willing to participate in the study, (5) able to complete self-recording, and (6) had a smartphone. Exclusion criteria were women who were pregnant or breast feeding, individuals with cardiovascular disease, and individuals currently enrolled in another smoking cessation program. The calculated sample size was 69 people per group (with alpha $=0.05$, two-tailed) and with a $80 \%$ power to reject the null hypothesis in quit rate at the 6 month follow-up. A dropout rate of $15 \%$ was estimated and so the sample size was increased to be about 80 smokers per group.

\section{Randomization}

Stratified random allocation was used to achieve equal assignment to the two groups. Stratification was done according to 3 factors: gender, nicotine dependence level as determined by Fagerstorm test (FTND) score, [20] and age. A computer-generated random sequence was used to assign participants to the intervention and control groups. The pharmacists enrolled the participants and then used a randomized table provided by the researcher to allocate participants to either the intervention group or the control group.

\section{Intervention group}

Smokers assigned to the intervention group met one-on-one with a community pharmacist at the community pharmacy. 
The duration of the first visit was around 30 minutes. The pharmacists asked if the participants were willing to quit smoking; if they agreed to join the study, and to complete a consent form. The pharmacists reassured the participants that choosing to quit was the best decision and emphasized the benefits of quitting. The pharmacists interviewed the participants for general information, intention to quit, struggles in quitting, history of attempting to quit, smoking habits, and nicotine dependence as determined by a Fagerstorm test (FTND). Blood pressure, weight, and exhaled carbon monoxide (CO), measured by a smokerlyzer, were measured by the pharmacists. The pharmacists then followed the treatment plans. The pharmacist checked the randomized table to see if the participant was in the intervention group and then registered their name to the web system, http://www.smokefreerx.com/, to get a username for the participant to login to the app. PharmQuit was then introduced and registered to the participant's mobile phone. At the end of the service, the pharmacist scheduled the next visit at the community pharmacy.

Nicotine gum, nortriptyline, sodium nitrate $0.5 \%$ mouth wash, Vernonia cinerea lozenges, and herbal medicine were options for participants who had FTND scores of at least 4, were smoking at least 10 cigarettes per day, or had a history of failure to quit smoking. Contraindications were checked before dispensing. The pharmacists counseled the participants on how to use the medication: drug name, dose, regimen, administration, duration of therapy, adverse effects, and disposal of nicotine gum. Pharmacists dispensed the medications following the smoking cessation practice guidelines of Thailand [21].

Follow-up visits were scheduled for Day 7, 14, 30, 60, 120, and 180. If participants were not able to keep to the schedule, the pharmacists followed-up by telephone, line, or Facebook messenger. Each follow-up visit took around 10 to 20 minutes. The pharmacists assessed smoking status, adherence to medication, adverse drug reactions, PharmQuit use, and their overall status to evaluate obstacles and provide encouragement. The pharmacists encouraged the participants to continue in the cessation program and did not blame them if progress had not been made. Blood pressure, weight, and exhaled $\mathrm{CO}$ were recorded by the pharmacists. At the end of the appointment, the pharmacists refilled medications and arranged for the next appointment.

\section{Control group}

Smokers assigned to the control group met one-on-one with a community pharmacist at the community pharmacy. Participants received usual pharmacy services on smoking cessation and medications, but had no access to PharmQuit.

\section{Measurements}

Pharmacists assessed outcomes at every visit. The baseline information assessed by pharmacists included socio-demographic characteristics, months of smoking, number of cigarettes smoked per day, FTND scores, quitting history, reasons for joining the study, and medications used for smoking cessation. Primary outcomes were quit rate, and number of cigarettes smoked per day. Secondary outcomes were adherence rate to the follow-up schedule, exhaled CO level, and satisfaction with PharmQuit. Quit rate was determined by counting the number of visits with the pharmacist since quitting. Exhaled $\mathrm{CO}$ was 
used to confirm the quit rate. Primary and secondary outcomes were measured at Day $0,7,14,30,60$, 120, and 180. Satisfaction with PharmQuit was evaluated only in the intervention group at Day 180.

\section{Data analysis}

Intention-to-treat was applied in this analysis. Descriptive statistics were presented for baseline. Categorical variables were compared by using the chi-squared test, and continuous data using the independent $t$ test for normally distributed data and the Mann-Whitney $U$ test for data that were not normally distributed. Estimates of effect and confidence intervals were analysed by using logistic regression. Data for participants with missing data were assumed to be the same as their last visit information. All test were two-sided and alpha was set to $5 \%$.

\section{Results}

We randomized a total of 156 participants to the intervention group or the control group. Completion on Day 180 was $30.8 \%(24 / 78)$ for the intervention group and $23.1 \%$ (18/78) for the control group (Fig. 1).

\section{Participant characteristics}

More medications were used by participants in the control group than in the intervention group. FTND in the control group was lower in the high nicotine addiction group than in the intervention group.

Nevertheless, there were no significant differences in all baseline characteristics between the two groups as shown in Table 1. 
Table 1

Baseline characteristics of participants in the intervention and control groups.

\begin{tabular}{|c|c|c|c|}
\hline \multirow[t]{2}{*}{ Characteristics } & $\begin{array}{l}\text { Intervention } \\
\text { group }\end{array}$ & $\begin{array}{l}\text { Control } \\
\text { group }\end{array}$ & \multirow[t]{2}{*}{$\begin{array}{l}\mathrm{p}- \\
\text { value }\end{array}$} \\
\hline & $\begin{array}{l}\text { No }(\%)(n= \\
78)\end{array}$ & $\begin{array}{l}\text { No }(\%)(n= \\
78)\end{array}$ & \\
\hline Gender: male & $71(91.0)$ & $72(92.3)$ & $0.772^{b}$ \\
\hline Age (years, mean \pm SD) & $33.5 \pm 14.3$ & $35.0 \pm 16.5$ & $0.533^{\mathrm{a}}$ \\
\hline Weight (Kg.) (mean \pm SD) & $69.1 \pm 14.3$ & $68.9 \pm 13.1$ & $0.947^{a}$ \\
\hline Blood pressure $(\mathrm{mmHg})(\mathrm{ni} / \mathrm{nc}=72 / 68)$ & $125.0 \pm 15.0$ & $\begin{array}{l}129.8 \pm \\
16.3\end{array}$ & $0.070^{\mathrm{a}}$ \\
\hline $\mathrm{SBP}($ mean $\pm \mathrm{SD})$ & \multirow[t]{2}{*}{$77.3 \pm 9.9$} & \multirow{2}{*}{$79.4 \pm 11.0$} & \multirow[t]{2}{*}{$0.234^{\mathrm{a}}$} \\
\hline $\mathrm{DBP}($ mean $\pm \mathrm{SD})$ & & & \\
\hline Underlying disease: yes & $24(30.8)$ & $25(32.1)$ & $0.908^{b}$ \\
\hline Length of time as a smoker (months) (mean \pm SD) & $182.5 \pm 165.0$ & $\begin{array}{l}196.5 \pm \\
175.5\end{array}$ & $0.621^{a}$ \\
\hline Number of cigarettes smoked per day (mean \pm SD) & $12.0 \pm 6.8$ & $12.4 \pm 8.2$ & $0.775^{a}$ \\
\hline $\begin{array}{l}\text { Fagerstrom test nicotine dependence (FTND) score (mean } \\
\pm \text { SD) }\end{array}$ & $3.7 \pm 2.4$ & $3.46 \pm 2.6$ & \multirow{4}{*}{$\begin{array}{l}0.589^{a} \\
0.896^{b}\end{array}$} \\
\hline - Score 7-10: high nicotine addiction 3 & $13(16.7)$ & $11(14.1)$ & \\
\hline - Score 4-6: moderate nicotine addiction 2 & $28(35.9)$ & $28(35.9)$ & \\
\hline - Score $<4$ : low nicotine addiction 1 & $37(47.4)$ & $39(50.0)$ & \\
\hline Use of smoking cessation medications: Yes & $40(51.3)$ & $44(56.4)$ & $0.521^{b}$ \\
\hline Close friends/family who smoke: yes $\left(n_{i} / n_{c}=53 / 50\right)$ & $50(75.8)$ & $45(71.4)$ & 0.577 \\
\hline Quit attempt in the past: yes $\left(n_{i} / n_{c}=60 / 57\right)$ & $61(81.3)$ & $64(87.7)$ & 0.287 \\
\hline $\begin{array}{l}\text { Longest period of abstinence in the past (days; mean } \pm \\
\text { SD) }\left(n_{i} / n_{c}=71 / 69\right)\end{array}$ & $117.0 \pm 328.8$ & $\begin{array}{l}123.3 \pm \\
209.6\end{array}$ & 0.892 \\
\hline
\end{tabular}

${ }^{a}$ Independent t-test, ${ }^{\mathrm{b}}$ Chi-square 


\begin{tabular}{|c|c|c|c|}
\hline \multirow[t]{2}{*}{ Characteristics } & $\begin{array}{l}\text { Intervention } \\
\text { group }\end{array}$ & $\begin{array}{l}\text { Control } \\
\text { group }\end{array}$ & \multirow[t]{2}{*}{$\begin{array}{l}\mathrm{p}- \\
\text { value }\end{array}$} \\
\hline & $\begin{array}{l}\text { No }(\%)(n= \\
78)\end{array}$ & $\begin{array}{l}\text { No }(\%)(n= \\
78)\end{array}$ & \\
\hline Smoking behaviors $\left(n_{\mathrm{i}} / \mathrm{n}_{\mathrm{c}}=76 / 75\right)$ & $53(69.7)$ & $50(66.8)$ & \multirow{2}{*}{$\begin{array}{l}0.095 \\
b\end{array}$} \\
\hline - After meals & $30(39.5)$ & $20(26.7)$ & \\
\hline - When drinking coffee & $56(73.7)$ & $49(65.3)$ & $\begin{array}{l}0.685 \\
b\end{array}$ \\
\hline - When drinking alcohol & & & $\begin{array}{l}0.265 \\
b\end{array}$ \\
\hline Psychological dependence $\left(n_{i} / n_{c}=76 / 75\right)$ & $44(57.9)$ & $36(40.0)$ & \multirow{2}{*}{$\begin{array}{l}0.223 \\
\mathrm{~b}\end{array}$} \\
\hline - Free time & $32(42.1)$ & $25(33.3)$ & \\
\hline - Working time & $48(63.2)$ & $47(62.7)$ & $\begin{array}{l}0.266 \\
b\end{array}$ \\
\hline - Stressful time & & & $\begin{array}{l}0.950 \\
b\end{array}$ \\
\hline Reasons for wanting to quit smoking $\left(n_{\mathrm{i}} / \mathrm{n}_{\mathrm{c}}=76 / 75\right)$ & $27(35.5)$ & $27(36.0)$ & \multirow{2}{*}{$\begin{array}{l}0.952 \\
b\end{array}$} \\
\hline - Family & $52(68.4)$ & $47(62.7)$ & \\
\hline - Health & $6(7.9)$ & $11(14.7)$ & $\begin{array}{l}0.457 \\
b\end{array}$ \\
\hline - Socially unacceptable & $6(7.9)$ & $12(10.0)$ & \multirow{2}{*}{$\begin{array}{l}0.188 \\
b\end{array}$} \\
\hline - Economic issue & $10(13.2)$ & $7(9.3)$ & \\
\hline \multirow[t]{2}{*}{ - Others (partners, stress) } & & & $\begin{array}{l}0.124 \\
b\end{array}$ \\
\hline & & & $\begin{array}{l}0.457 \\
b\end{array}$ \\
\hline${ }^{\mathrm{a}}$ Independent t-test, ${ }^{\mathrm{b}}$ Chi-square & & & \\
\hline
\end{tabular}

\section{Clinical outcomes}

The number of cigarettes smoked per day was not significantly different between the intervention and control groups at each follow up visit. However, the number of cigarettes smoked per day at Day 180 decreased significantly when compared with Day 0 in both groups $(p<0.05)$ as shown in Table 2. 
Table 2

Comparisons of number of cigarettes smoked per day between the intervention and control groups at Day $0,7,14,30,60,120$ and 180

\begin{tabular}{|c|c|c|c|c|c|}
\hline \multirow[t]{2}{*}{ Visit } & \multicolumn{2}{|l|}{ Intervention group $(\mathrm{n}=78)$} & \multicolumn{2}{|l|}{ Control group $(n=78)$} & \multirow{2}{*}{$\begin{array}{l}\text { p- } \\
\text { value }^{a}\end{array}$} \\
\hline & $\begin{array}{l}\text { Number of cigarettes } \\
\text { smoked per day Mean } \pm S D\end{array}$ & $\begin{array}{l}\text { Mean } \\
\text { difference }\end{array}$ & $\begin{array}{l}\text { Number of cigarettes } \\
\text { smoked per day Mean } \pm S D\end{array}$ & $\begin{array}{l}\text { Mean } \\
\text { difference }\end{array}$ & \\
\hline $\begin{array}{l}\text { Day } \\
0\end{array}$ & $11.8 \pm 6.8$ & & $13.2 \pm 8.5$ & & 0.775 \\
\hline $\begin{array}{l}\text { Day } \\
7\end{array}$ & $7.3 \pm 6.8$ & $4.4 \pm 7.1^{\star \star}$ & $6.8 \pm 7.9$ & $6.2 \pm 9.0^{\star \star}$ & 0.479 \\
\hline $\begin{array}{l}\text { Day } \\
14\end{array}$ & $5.0 \pm 5.8$ & $6.7 \pm 7.9^{\star *}$ & $5.2 \pm 7.1$ & $7.8 \pm 9.2^{\star \star}$ & 0.948 \\
\hline $\begin{array}{l}\text { Day } \\
30\end{array}$ & $4.5 \pm 5.3$ & $7.2 \pm 7.8^{* *}$ & $3.1 \pm 3.8$ & $10.0 \pm 9.4^{\star \star}$ & 0.188 \\
\hline $\begin{array}{l}\text { Day } \\
60\end{array}$ & $4.4 \pm 5.6$ & $7.3 \pm 7.7^{* *}$ & $3.1 \pm 4.1$ & $9.9 \pm 9.5^{* *}$ & 0.235 \\
\hline $\begin{array}{l}\text { Day } \\
120\end{array}$ & $3.7 \pm 5.0$ & $8.0 \pm 7.7^{\star *}$ & $2.9 \pm 3.9$ & $10.2 \pm 9.3$ & 0.407 \\
\hline $\begin{array}{l}\text { Day } \\
180\end{array}$ & $3.5 \pm 5.0$ & $8.2 \pm 7.6^{* *}$ & $2.9 \pm 4.0$ & $\underset{* \star}{10.2 \pm 9.4}$ & 0.513 \\
\hline \multicolumn{6}{|c|}{$\begin{array}{l}\text { a Comparing the number of cigarettes smoked per day between groups by using the Independent t- } \\
\text { test }\end{array}$} \\
\hline \multicolumn{6}{|c|}{${ }^{\star \star} p<0.001$, within group comparison using Day 0 as a reference by pair t-test } \\
\hline
\end{tabular}

There was no significant difference in quit rate between both groups in all visits. Both groups showed significant improvement in abstinence rates compared with their respective Day $0(p<0.05)$ as shown in Table 3. There were a total of 7 participants who relapsed after quitting. Two participants $(28.6 \%)$ in the intervention group relapsed at Day 14 and Day 30. Five participants (71.4\%) in the control group relapsed at Day 14 (2 participants), Day 30 (2 participants), and Day 60 (1 participant). The proportion of participants who exhaled CO lower than 7 ppm significantly increased compared with Day 0 in both groups $(p<0.05)$. Nevertheless, there was no significant difference when comparing between groups as shown in Table 4. Of the 29 participants in the intervention group who accessed PharmQuit continuously, 12 were $(41.3 \%)$ were successful in quitting and 17 (58.6\%) failed to quit smoking. 
Table 3

Comparisons of quit rate between the intervention and control groups at Day $0,7,14,30,60,120$, and 180

\begin{tabular}{|c|c|c|c|c|c|}
\hline \multirow[t]{2}{*}{ Visit } & Intervention group $(n=78)$ & Control group $(n=78)$ & \multirow[t]{2}{*}{ OR } & \multirow[t]{2}{*}{$95 \% \mathrm{Cl}$} & \multirow[t]{2}{*}{$\mathrm{p}$-value } \\
\hline & Quit rate No (\%) & Quit rate No (\%) & & & \\
\hline Day 0 & $0(0.0)$ & $0(0.0)$ & $\mathrm{n} / \mathrm{a}$ & $\mathrm{n} / \mathrm{a}$ & $\mathrm{n} / \mathrm{a}$ \\
\hline Day 7 & $14(18.0)$ & 15 (19.2) & 0.93 & $0.44-1.97$ & 0.848 \\
\hline Day 14 & $18(23.1)$ & $20(25.6)$ & 0.83 & $0.41-1.67$ & 0.591 \\
\hline Day 30 & $18(23.1)$ & $20(25.6)$ & 0.88 & $0.43-1.78$ & 0.718 \\
\hline Day 60 & $23(29.5)^{\#}$ & $25(32.1) \#$ & 0.94 & $0.48-1.85$ & 0.863 \\
\hline Day 120 & $25(32.1) \#$ & $25(32.1) \#$ & 1.00 & $0.51-1.96$ & 1.000 \\
\hline Day 180 & $25(32.1){ }^{\#}$ & $27(34.6)$ \# & 1.00 & $0.51-1.95$ & 1.000 \\
\hline \multicolumn{6}{|c|}{${ }^{b}$ Comparing the quit rate between groups by using the logistic regression } \\
\hline \multicolumn{6}{|c|}{$\# p<0.05$, within group comparison using Day 7 as a reference by using the McNemar test } \\
\hline
\end{tabular}


Table 4

Comparisons of carbon monoxide (CO) levels between the intervention and control groups at Day $0,7,14,30,60,120$ and 180

\begin{tabular}{|c|c|c|c|c|c|}
\hline \multirow[t]{2}{*}{ Visit } & Intervention group $(n=74)$ & $\begin{array}{l}\text { Control group } \\
(n=76)\end{array}$ & OR & $95 \% \mathrm{Cl}$ & \multirow[t]{2}{*}{$p$-value ${ }^{c}$} \\
\hline & CO <7 ppm No (\%) & $\mathrm{CO}<7 \mathrm{ppm}$ No $(\%)$ & & & \\
\hline Day 0 & $24(32.4)$ & $24(31.6)$ & 1.04 & $0.52-2.07$ & 0.911 \\
\hline Day 7 & $30(40.5)$ & $32(42.1)^{*}$ & 0.94 & $0.49-1.80$ & 0.846 \\
\hline Day 14 & $29(39.2)$ & $36(47.4)^{*}$ & 0.72 & $0.37-1.37$ & 0.313 \\
\hline Day 30 & $33(44.6)^{*}$ & $38(50.0)^{*}$ & 0.81 & $0.42-1.53$ & 0.508 \\
\hline Day 60 & $36(48.7)^{*}$ & $38(50.0)$ * & 0.95 & $0.50-1.80$ & 0.869 \\
\hline Day 120 & $32(43.2)$ & $38(50.0)^{*}$ & 0.76 & $0.40-1.45$ & 0.407 \\
\hline Day 180 & $36(48.7)^{*}$ & $40(52.6)^{*}$ & 0.85 & $0.45-1.62$ & 0.626 \\
\hline $\begin{array}{l}\text { CO stan } \\
{ }^{c} \text { Compa } \\
{ }^{*} p<0.05,\end{array}$ & $\begin{array}{l}\text { s for exhaled carbon monox } \\
\text { ig exhaled co between grou } \\
\text { ithin group comparison usin }\end{array}$ & $\begin{array}{l}\text { e, ppm stands for pa } \\
\text { s by using the logisti } \\
\text { Day } 0 \text { as a referenc }\end{array}$ & $\begin{array}{l}\text { per } m \\
\text { regres } \\
\text { by usir }\end{array}$ & ion & 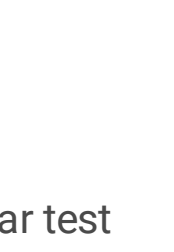 \\
\hline
\end{tabular}

\section{Adherence to the smoking cessation program}

Adherence to the smoking cessation program in both the intervention and control groups was assessed. Table 5 shows that adherence rate decreased over time, and adherence was higher in the intervention group than the control group. The number of days in the cessation program was analyzed and there was no significant difference between the intervention (73.4 \pm 76.1 days) and control groups $(60.1 \pm 70.8$ days $)(p=0.232)$. 
Table 5

The adherence rate to the smoking cessation program in the intervention and control groups

\begin{tabular}{|c|c|c|c|c|c|}
\hline \multirow[t]{3}{*}{ Day } & \multicolumn{2}{|l|}{ Adherence rate } & \multirow[t]{3}{*}{ OR } & \multirow[t]{3}{*}{$95 \% \mathrm{Cl}$} & \multirow[t]{3}{*}{ p-value ${ }^{d}$} \\
\hline & Intervention group $(n=78)$ & Control group $(n=78)$ & & & \\
\hline & No (\%) & No (\%) & & & \\
\hline 1 day & 78 (17.95) & 78 (23.08) & $\mathrm{n} / \mathrm{a}$ & $\mathrm{n} / \mathrm{a}$ & $\mathrm{n} / \mathrm{a}$ \\
\hline 7 days & $64(82.05)$ & $60(76.92)$ & 1.37 & $0.63-3.00$ & 0.429 \\
\hline 14 days & $54(69.23)$ & $55(70.51)$ & 0.94 & $0.48-1.87$ & 0.861 \\
\hline 30 days & $47(60.26)$ & $43(55.13)$ & 1.23 & $0.65-2.33$ & 0.517 \\
\hline 60 days & $36(46.15)$ & $28(35.90)$ & 1.53 & $0.81-2.91$ & 0.194 \\
\hline 120 days & $28(35.90)$ & $21(26.92)$ & 1.52 & $0.77-3.00$ & 0.228 \\
\hline 180 days & $24(30.77)$ & $18(23.08)$ & 1.39 & $0.68-2.86$ & 0.364 \\
\hline
\end{tabular}

Of the 78 participants in the intervention group, $37.2 \%$ were using PharmQuit at month 1. After six months, only 2.6\% were using PharmQuit as shown in Fig. 2. The number of times PharmQuit was accessed was highest during the 1st month, and then decreased over time. At day 180, 14 out of 78 participants (response rate 17.9\%) returned the PharmQuit satisfaction questionnaire. They rated it the highest for design, appearance, and the objective of PharmQuit. The overall satisfaction with PharmQuit was high in all questions. The top three highest scores on individual questions were satisfaction with the amount of information on each screen, satisfaction with the font and font size, and the help to keep service schedules. The lowest score was humorous and interesting features, and challenging and attractive interactive features as shown in Table 6. 
Table 6

Satisfaction score (on a scale of 1-5) to PharmQuit

Application PharmQuit

Mean \pm

SD

$(n=14)$

Dimension 1: Objective to quit smoking

$4.1 \pm 09$

1. You are satisfied with PharmQuit in helping you to keep service schedules.

$4.3 \pm 1.0$

2. You are satisfied with the progress feature.

$4.1 \pm 1.1$

3. You are satisfied with the encouragement received

$4.1 \pm 0.9$

4. You are satisfied with question and answer section.

$4.2 \pm 0.9$

5. You are satisfied that PharmQuit has helped you quit or reduce the number of

$3.9 \pm 1.1$ cigarettes smoked.

Dimension 2: Scope of application

$4.0 \pm 0.9$

6. You are satisfied with the number of functions.

$3.9 \pm 1.1$

7. You are satisfied with interactive functions between a pharmacist and other smokers.

$4.2 \pm 1.0$

8. You are satisfied with the ease of inputting your personal information.

$3.9 \pm 1.2$

9. You are satisfied with the privacy of your information.

$4.0 \pm 1.0$

Dimension 3: Format and interactive between PharmQuit and the user

$4.0 \pm 1.0$

10. You are satisfied with the daily encouraging messages and reminders.

$4.1 \pm 1.2$

11. You are satisfied with the response speed of the application.

$4.1 \pm 0.9$

12. You are satisfied with humorous and interesting features.

$3.8 \pm 1.1$

13. You are satisfied with the challenging and attractive interactive features.

$3.7 \pm 1.3$

Dimension 4: Design

$4.2 \pm 0.9$

14. You are satisfied with characteristics of the app.

$4.1 \pm 1.1$

15. You are satisfied with the amount of information on each screen.

$4.4 \pm 0.9$

16. You are satisfied with the sequence of each group of functions.

$4.2 \pm 0.8$

17. You are satisfied with the convenience and ease of use of PharmQuit.

$4.2 \pm 0.8$

Dimension 5: Appearance

$4.1 \pm 1.0$

18. You are satisfied with attractiveness and usability of the app.

$4.1 \pm 1.0$

19. You are satisfied with the font and background color.

$4.1 \pm 1.1$

20. You are satisfied with the font and font size.

$4.4 \pm 0.9$

Page $13 / 23$ 


\section{Discussion}

Participants in both groups significantly benefited from the smoking cessation program provided by community pharmacists. Although there were no significant differences between the intervention and control groups, participants in both groups showed improvement in quit rate, number of cigarettes smoked per day, exhaled $\mathrm{CO}$, and adherence to the cessation program. Adherence to the cessation program was higher in the intervention group (74 days) than the control group (60 days). Also, the relapse rate in the intervention group was lower than the control group. This good probably be due to the motivation provided through PharmQuit as the participants in the intervention group were highly satisfied with PharmQuit.

In this study, the quit rates in the intervention group tended to be lower than the control group in most of follow-up visits, but this difference was not statistically significant. The findings from other studies using different mobile apps are not consistent. For example, in a study by Herbec et al, carried out in 300 community pharmacies in the UK, the results after 8 weeks showed a quit rate of $25 \%$ in the intervention group (using the NRT2Quit app) and $8 \%$ in the control group $(p=0.19)$ [17]. A study by Nomura et al in Japan showed no significant difference in continuous abstinence rates between telemedicine counselling plus CureApp and face-to-face clinical visits plus CureApp (81.0\% vs $78.9 \%$ ) [22]. Another double-blind RCT study by Bricker et al compared two apps (SmartQuit and QuitGuide) over two months. This study showed quit rates of $13 \%$ in SmartQuit and $8 \%$ in QuitGuide $(p>0.05)$ [23]. However, a study on physicians and CureApp by Masaki et al in Japan showed a significant difference between the intervention group using CureApp and a control group using a control-app (63.9\% vs 50.5\%) [24].

The magnitude of the quit rates in this study are similar to those of other pharmacist-led smoking cessation programs conducted elsewhere. One randomized controlled trial (RCT) study in Qatar by Hajj et al evaluated smoking cessation rates provided by pharmacists at 6 months and found a quit rate of $27.0 \%$ [25]. Gong et al did an RCT study with participants who received pharmacist-provided telephone counseling and medications showed a 42.3\% 1-week point abstinence rate at week 12 which was higher than the usual care rate of $38.2 \%(p>0.05)$ [26]. When compared with the PharmQuit study, these cessation rates are similar or better than two studies that evaluated the effectiveness of the apps without services from health professionals. The first was a single arm study by lacoviello et al in the US using the Clickotine app for 8 weeks, which showed a self-reported abstinence rate of $26.2 \%$ [18]. However, the other study by Bricker et al, showed a lower quit rate (13\% in SmartQuit and $8 \%$ in QuitGuide) when compared to our study [23]. 
Although most participants in the intervention group liked PharmQuit, participants accessed it less frequently over time. Some explained that they had limited internet access. One participant complained that there were too many messages being sent (twice per day). Frequent messages may be counterproductive because Do et al showed that daily texts were less effective than weekly texts [27]. One participant uninstalled PharmQuit due to limited memory on his phone. One participant forgot to do the daily record on PharmQuit because there was no feedback from his pharmacist. Some participants who were able to quit smoking stopped using PharmQuit after quitting. At the start of recruitment of participants, the login feature was not functioning and this delayed recruitment by a week. This might not have left a good impression on the particpants in the intervention group. These factors may explain the low rate of active users of PharmQuit even though all participants in the intervention group were trained to use PharmQuit by their pharmacists at the start of the program. However, when considering that the aim of PharmQuit was to help participants adhere to the program using an easy-to-use app, the aims was achieved.

Another explanation for the results was high loss to follow-up rate in both groups. Although the pharmacists reminded the participants about the appointments and made calls, most of them could not be reached by phone. This may have reduced the power of the study to show significant differences in smoking cessation rates between the two groups. One participant in the intervention group was diagnosed with cancer and decided to stop using this app. Other studies have shown that special characteristics such as swearing to complete the study [22], much better compensation ( 90 US dollars per visit) [24], and effective medications (such as varenicline, bupropion, nicotine patch) [22, 24-26] helped to increase app engagement and quit rate. Our study was performed ethically and the participants could choose to leave the study at any time. A small compensation was given and any needed medications were provided free of charge. The most effective medication for smoking cessation in our study was nicotine gum which has been shown to be less effective than some other medications in other studies [28]. As only $51-56 \%$ of participants received medications, participants who did not get medications may have thought it was not necessary or worthwhile to come and talk to the community pharmacists.

The study had some limitations. A substantial number of participants had missing data during the follow-up visits. The low compensation may not have been a sufficient incentive to convince people to join the study and to complete the study. Although participants who were participating in other cessation programs during recruitment were excluded, no follow-up was done to find out if they had started another cessation program during the study. PharmQuit was developed for this study only in Thai, so the use of PharmQuit outside of Thailand would be limited to countries where reading Thai is common, such as Lao P.D.R.

The strength of the study was that it was a multicenter study that used a randomized control design, and had a long follow-up duration. Some of the community pharmacists in this study had experience serving at a university with a smoke-free campus policy [29].

\section{Conclusion}


The results showed benefit that community pharmacist provide in helping smokers quit smoking. PharmQuit was not more effective than just pharmacist counselling. Nevertheless, it may help pharmacists get better adherence to a smoking cessation program. The use of a mobile app is thus one option for smokers in larger clinical trials looking at smoking cessation.

\section{Declarations}

\section{Acknowledgements}

We are grateful for the contributions of Asst. Prof. Krongjit Vathesatogkit, RN, Asst. Prof. Theerapong Seesin, Pharm.D, BCPs, Asst. Prof. Dr. Saithip Suttiruksa, Charnkiat Phianchana, Pharm.D., high school students in Kaengkhro Industrial and Community Education College, and the team of programmers at the Faculty of Informatics for PharmQuit development. We wish to thank Prof. P.T. Thomas for his kind comments on the methodology and proofreading. We also wish to thank native English speaker, Mr. Douglas Olson for proofreading. We are thankful for the seven community pharmacies, batch 14 Pharm.D. students from Mahasarakham University, health care providers in Takhonyang Sub-district and Khamrieng Sub-district for helping to recruit participants and being extremely supportive in this study.

\section{Funding}

This study was supported by the Health Security Office region 7 Khon Kaen [PO, grant number 60/B/00293], Health Promotion Smoke Free Pharmacy Network, Community Pharmacy Foundation, and Thai Health Promotion Foundation [PO, grant number 63-05-009].

\section{Availability of data and materials}

The datasets used and/or analyzed during this study are available from the corresponding author on request.

\section{Authors' contributions}

NA was the principal investigator in the study. He was responsible for the initial concept of the study, literature review, drafting the plan of the study, application development, data collection, analysis and interpretation of the data, and writing the first draft of the manuscript. PO was responsible for the research funding, the initial concept and design of the study, assisting with application development, data collection, analysis and interpretation of data, finalizing and approving the manuscript, and submitting it to the journal. JK was responsible for the initial concept and design of the study, and assisted with the development of the app, interpretation of data, and approving the manuscript. PT and BS were responsible for the initial concept of the study and design-mainly for application development, and 
approving the manuscript. CS and SS were responsible for the initial concept and design of the study, data collection, and approving the manuscript.

\section{Competing interest}

We undersigned confirm that we do not have any competing interests which would influence the study.

\section{Consent for publication}

Not applicable. The manuscript does not report individual data.

\section{Ethical approval and consent to participant}

The study protocol, consent forms, and tools received ethical approval by Mahasarakham University (ID: 033/2559). The participants provided written and informed consent to participate in this study.

\section{Author details}

${ }^{1}$ The Primary Care Practice Research Unit, Faculty of Pharmacy, Mahasarakham University, Khamrieng Sub-District, Kantarawichai District, Maha Sarakham Province, 44150, Thailand, Tel/fax +66-(0)43754360

2 The Clinical Pharmacy Research Unit, Faculty of Pharmacy, Mahasarakham University, Khamrieng SubDistrict, Kantarawichai District, Maha Sarakham Province, 44150, Thailand, Tel/fax +66-(0)4375-4360

${ }^{3}$ Faculty of Informatics, Mahasarakham University, Khamrieng Sub-District, Kantarawichai District, Maha Sarakham Province, 44150, Thailand

\section{References}

1. Taylor AL, Bettcher DW. WHO Framework Conventional on Tobacco Control: a global "good" for public health. Bull World Health Organ. 2000;78(7):920-9.

2. GBD 2017 Risk Factor Collaborators. Global, regional, and national comparative risk assessment of 84 behavioural, environmental and occupational, and metabolic risks or clusters of risks for 195 countries and territories, 1990-2017: a systematic analysis for the Global Burden of Disease Study 2017. Lancet 2018; 392:1923-94.

3. Global NCD target: reducing tobacco use. 2016. https://www.who.int/beat-ncds/take-action/ncdtobacco-target.pdf. Accessed July 2, 2020. 
4. Aungkulanon S, Pitayarangsarit S, Bundhamcharoen K, Akaleephan C, Chongsuvivatwong V, Phoncharoen $\mathrm{R}$, et al. Smoking prevalence and attributable deaths in Thailand: predicting outcomes of different tobacco control interventions. BMC Public Health. 2019;19:984.

5. Lancaster T, Stead LF. Individual behavioural counselling for smoking cessation. Cochrane Database Syst Rev. 2005;2.DOI: 10.1002/14651858.CD001292.pub2.PMID: 15846616.

6. Hartmann-Boyce J, Chepkin SC, Ye W, Bullen C, Lancaster T. Nicotine replacement therapy versus control for smoking cessation. Cochrane Database Syst Rev. 2018;5(5). DOI:

10.1002/14651858.CD000146.pub5.

7. Van Eerd EAM, van der Meer RM, van Schayck OCP, Kotz D. Smoking cessation for people with chronic obstructive pulmonary disease. Cochrane Database Syst Rev. 2016;8. DOI: 10.1002/14651858.CD010744.pub2.

8. Saba M, Diep J, Saini B, Dhippayom T. Meta-analysis of the effectiveness of smoking cessation interventions in communicy pharmacy. J Clin Pharm Ther. 2014;39:240-247.

9. Brown TJ, Todd A, O'Malley C, Moore HJ, Husband AK, Bambra C, et al. Community pharmacydelivered interventions for public health priorities: A systematic review of interventions for alcohol reduction, smoking cessation and weight management, including meta-analysis for smoking cessation. BMJ open. 2016;6:e009828.

10. O’Reilly E, Frederick E, Palmer E. Models for pharmacist-delivered tobacco cessation services: a systematic review. J Am Pharm Assoc. 2019;59:42-752.

11. Brett K, Yenug SST, Ford C. Pharmacist-led interventions for tobacco smoking cessation: a review of clinical effectiveness and cost-effectiveness. CADTH Rapid Response Report: Summary with Critical Appraisal. Ottawa (ON): Canadian Agency for Drugs and Technologies in Health; 2019; https://europepmc.org/article/NBK/NBK549529. Accessed July 2, 2020.

12. Cantor SB, Deshmukh AA, Luca NS, Nogueras-Gonzalez GM, Rajan T, Prokhorov AV. Costeffectiveness analysis of smoking-cessation counseling training for physicians and pharmacists. Addict Behav. 2015;45:79-86.

13. Bussaratid S, Siripaiboonkij A. Study of Smoking Cessation Rate at Smoking Cessation Clinic, Siriraj Hospital, Thailand. J Psychiatr Assoc Thailand. 2012;57:305-312.

14. Haskins BL, Lesperance D, Gibbons P, Boudreaux ED. A systematic review of smartphone applications for smoking cessation. TBM. 2017;7:292-299.

15. Hoeppner BB, Hoeppner SS, Seaboyer L, Schick MR, Wu GW, Bergman BG, et al. How smart are smartphone apps for smoking cessation? A content analysis. Nicotine Tob Res. 2015;18:1025-1031.

16. Whittaker R, McRobbie H, Bullen C, Borland R, Rodgers A, Gu Y. Mobile phone-based interventions for smoking cessation. Cochrane Database Syst Rev. 2012;11. DOI:

10.1002/14651858.CD006611.pub3.

17. Herbec A, Brown J, Shahab L, West R, Raupach T. Pragmatic randomized trial of a smartphone app (NRT2Quit) to improve effectiveness of nicotine replacement therapy in a quit attempt by improving medication adherence: results of prematurely terminated study. Trials. 2019;20:547. 
18. lacoviello BM, Steinerman JR, Klein DB, Silver TL, Berger AG, Luo SX, Schork NJ. Clickotine, a personalized smartphone app for smoking cessation: initial evaluation. JMIR Mhealth Uhealth. 2017;5(4): e56.

19. Schulz KF, Altman DG, Moher D, CONSORT Group. Consort 2010 statement: updated guidelines for reporting parallel group randomized trials. BMJ. 2010;23(340): c332. DOI:10.1136/bmj.c332.

20. Rustin TA. Assessing nicotine dependence. Am Fam Physician. 2000;62(3):579-584.

21. Rungruanghiranya S, Sunthorntham S. Smoking cessation practice guideline in Thailand. Health Promotion Foundation. Electronic book; 2012.

22. Nomura A, Tanigawa T, Muto T, Oga T, Fukushima Y, Kiyosue A, Miyazake M, Hida E, Satake K. Clinical efficacy of telemedicine compared to face-to-face clinic visits for smoking cessation: multicenter open-label randomized controlled noninferiority trial. J Med Internet Res. 2019;21(4):e13520.

23. Bricker JB, Mull K, Kientz JA, Vilardaga RM, Mercer LD, Akioka K, et al. Randomized, controlled pilot trial of a smartphone app for smoking cessation using acceptance and commitment therapy. Drug Alcohol Depend. 2014;1(143):87-94.

24. Masaki K, Tateno H, Nomura A, Muto T, Suzuki S, Stake K, et al. A randomized controlled trial of a smoking cessation smartphone application with a carbon monoxide checker. Npj Digital Medicine. 2020;3 (35). https://doi.org/10.1038/s41746-020-0243-5

25. Hajj MSE, Kheir N, Mulla AHA, Shami R, Fanous N, Mahfound ZR. Effectiveness of a pharmacistdelivered smoking cessation program in the State of Qatar: a randomized controlled trial. BMC Public Health. 2017;17:215. DOI 10.1186/s12889-017-4103-4.

26. Gong J, Baker CL, Zou KH, Bruno M, Jumadilova Z, Lawrence D, et al. A pragmatic randomized trial comparing telephone-based enhanced pharmacy care and usual care to support smoking cessation. J Mang Care Spec Pharm. 2016;22(12):1417-25.

27. Do HP, Tran BX, Pham QL, Nguyen LH, Tran TT, Latkin CA, et al. Which eHealth interventions are most effective for smoking cessation? A systematic review. Patient Prefer Adher. 2018;2: 2065-2084.

28. Stead LF, Perera R, Bullen C, Mant D, Lancaster T. Nicotine replacement therapy for smoking cessation. Cochrane Database of Systematic Reviews. 2008;1.DOI:

10.1002/14651858.CD000146.pub3.

29. Sookaneknun S, Sookaneknun P, Seesin T, Bunditanukul K, Phianchana P, Sirithanawuthichai T, Promarak T, Sanseeha L, Phutiya C, Trisat N, and Praratpoomee P. Outcomes of a two-year smokefree university and organizational policy management. MJPHM. 2018;18(2):109-122.

\section{Figures}


Excluded ( $\mathrm{n}=4)$ :

Not meeting inclusion criteria $(n=4)$

Randomised ( $\mathrm{n}=156)$

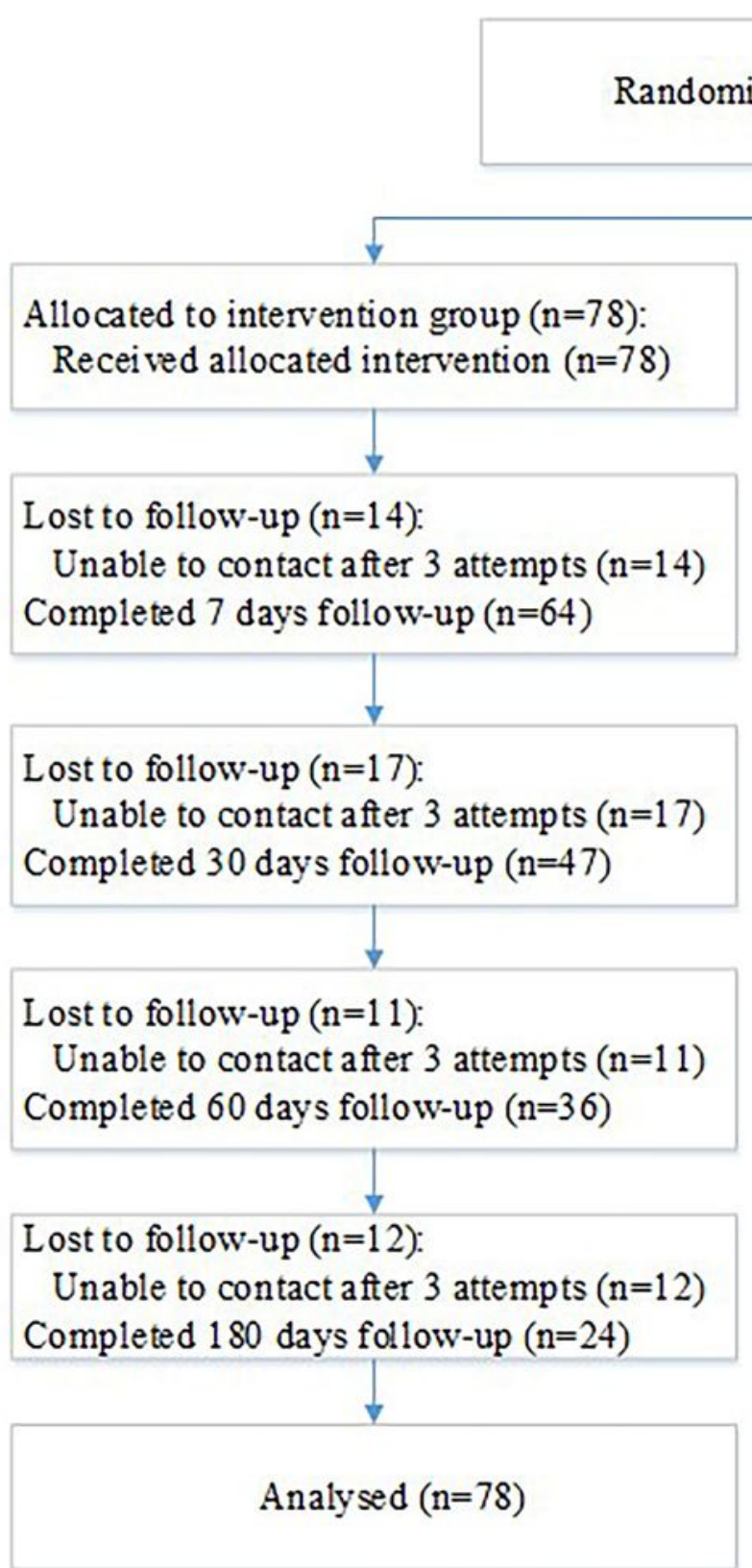

Allocated to control group ( $\mathrm{n}=78)$ :

Received allocated control $(n=78)$

Lost to follow-up $(n=18)$ :

Unable to contact after 3 attempts ( $n=18$ )

Completed 7 days follow-up $(n=60)$

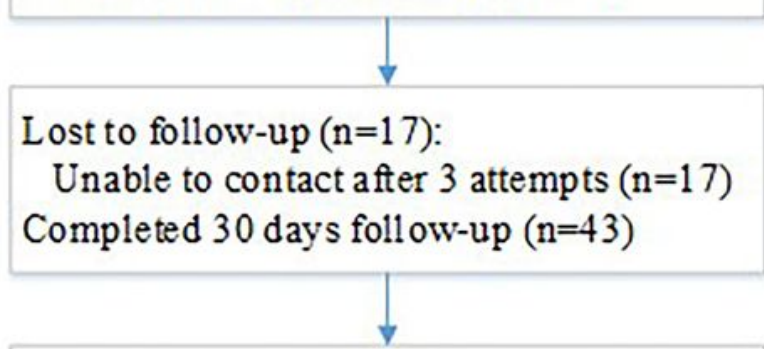

Lost to follow-up ( $\mathrm{n}=15)$ :

Unable to contact after 3 attempts ( $n=15$ ) Completed 60 days foll ow-up $(n=28)$

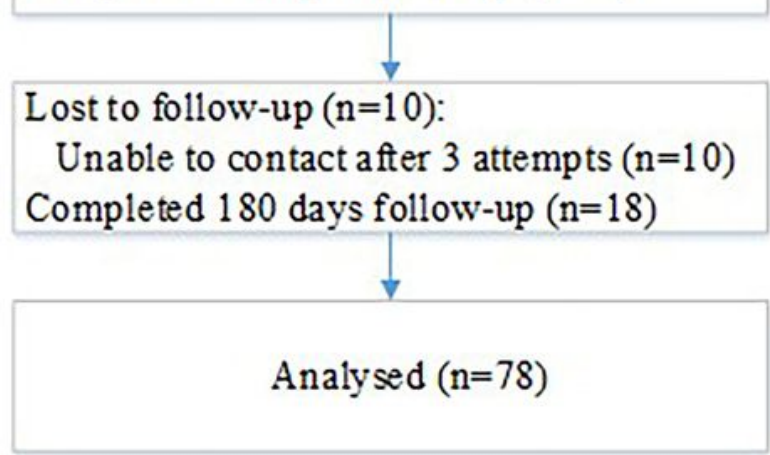

\section{Figure 1}

Participant flowchart 
Excluded ( $\mathrm{n}=4)$ :

Not meeting inclusion criteria $(n=4)$

Randomised $(\mathrm{n}=156)$

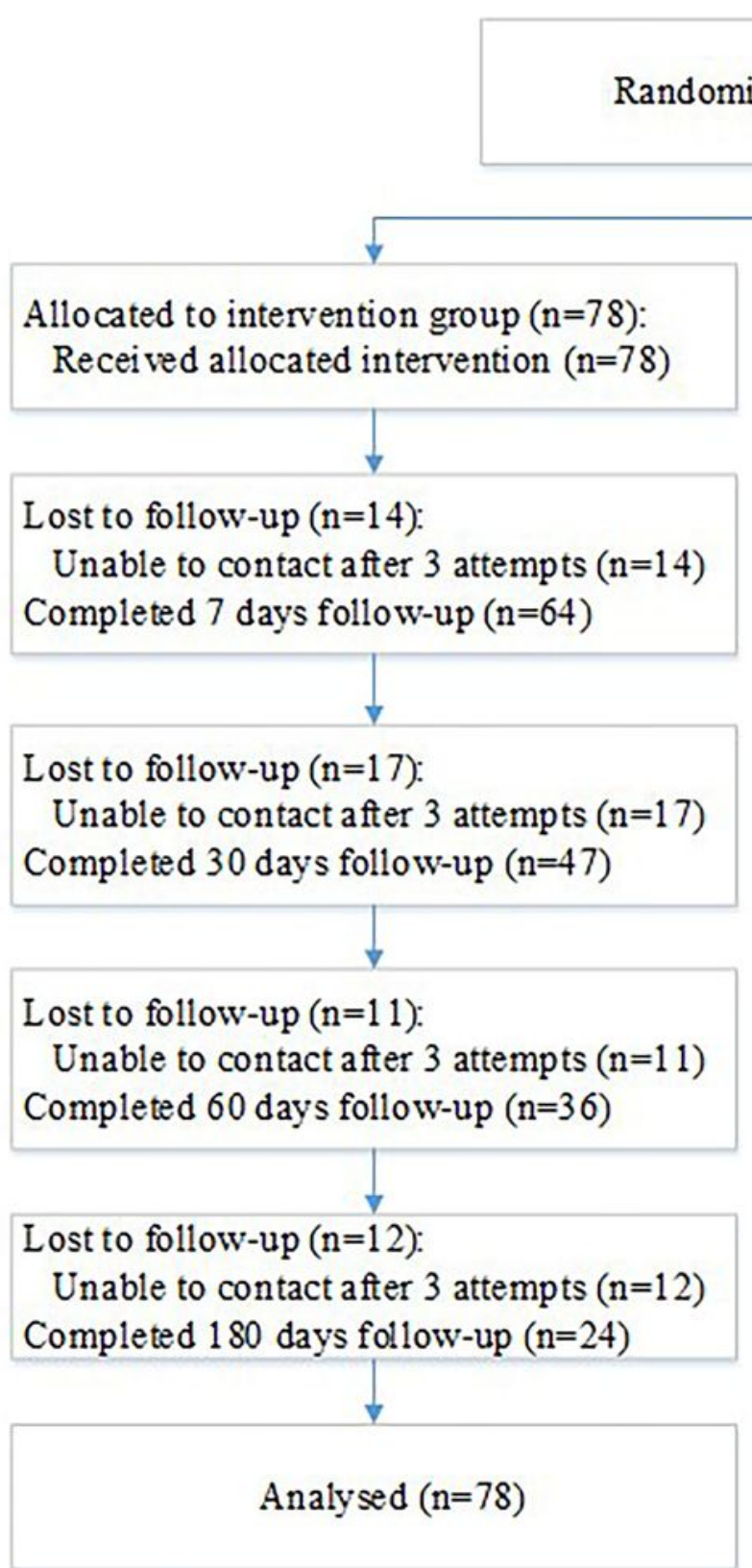

Allocated to control group ( $\mathrm{n}=78)$ :

Received allocated control $(n=78)$

Lost to follow-up $(n=18)$ :

Unable to contact after 3 attempts ( $n=18$ )

Completed 7 days follow-up $(n=60)$

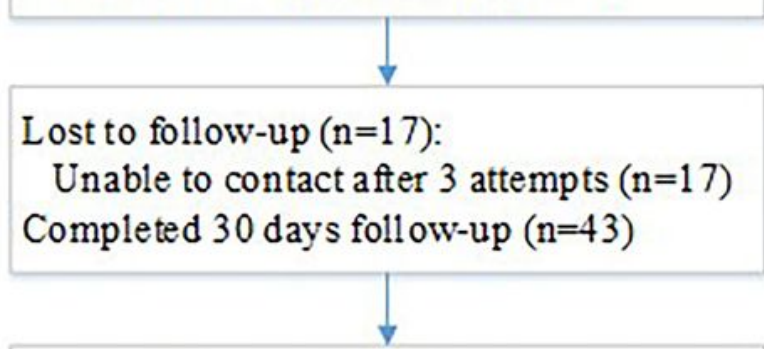

Lost to follow-up ( $n=15)$ :

Unable to contact after 3 attempts ( $n=15$ ) Completed 60 days foll ow-up $(n=28)$

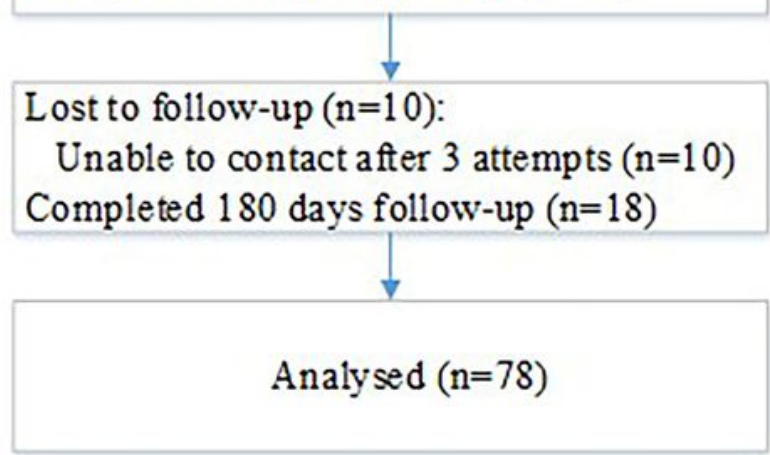

\section{Figure 1}

Participant flowchart 


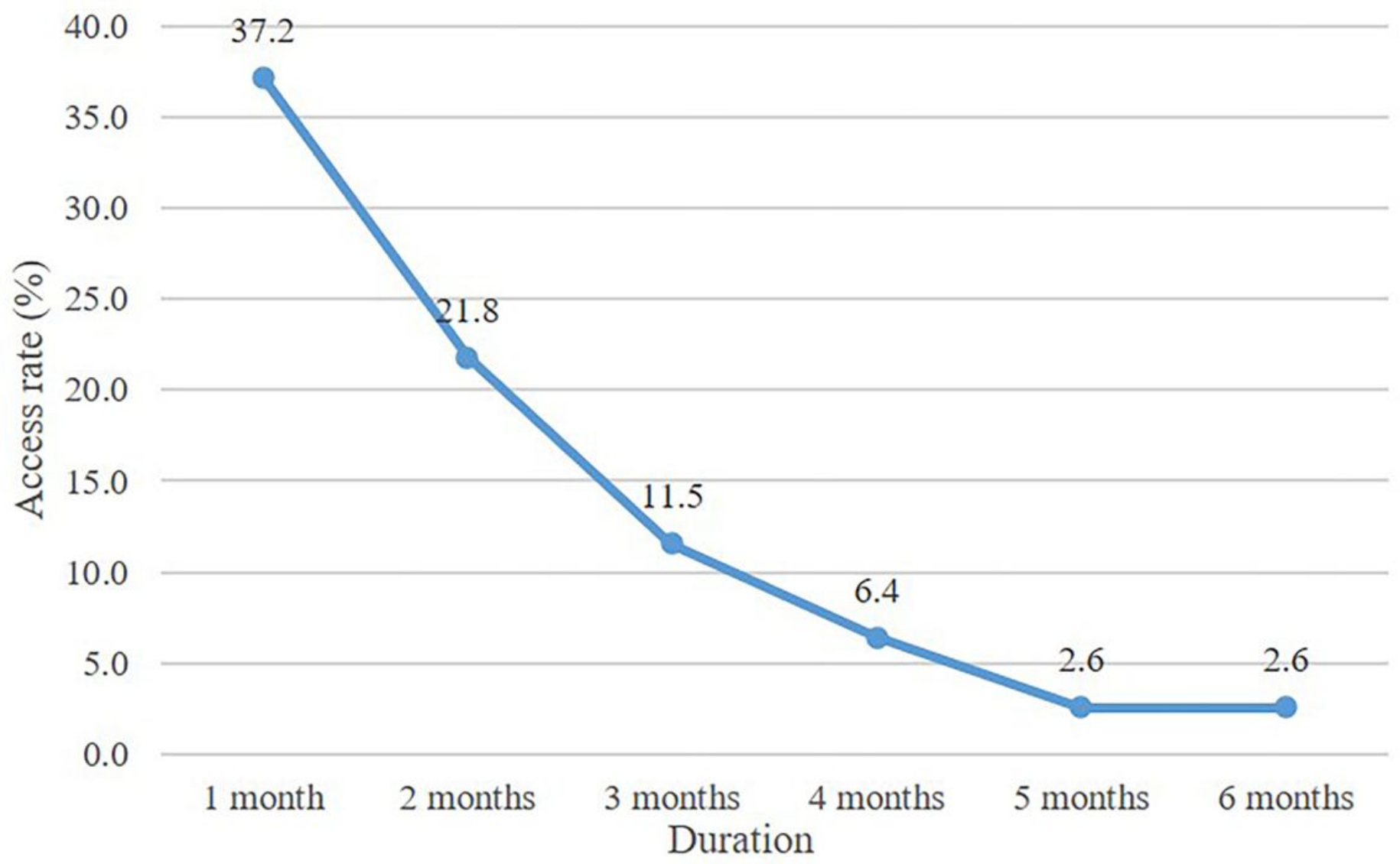

Figure 2

The access rate to PharmQuit in the intervention group within the 6 month follow-up ( $n=78)$ 


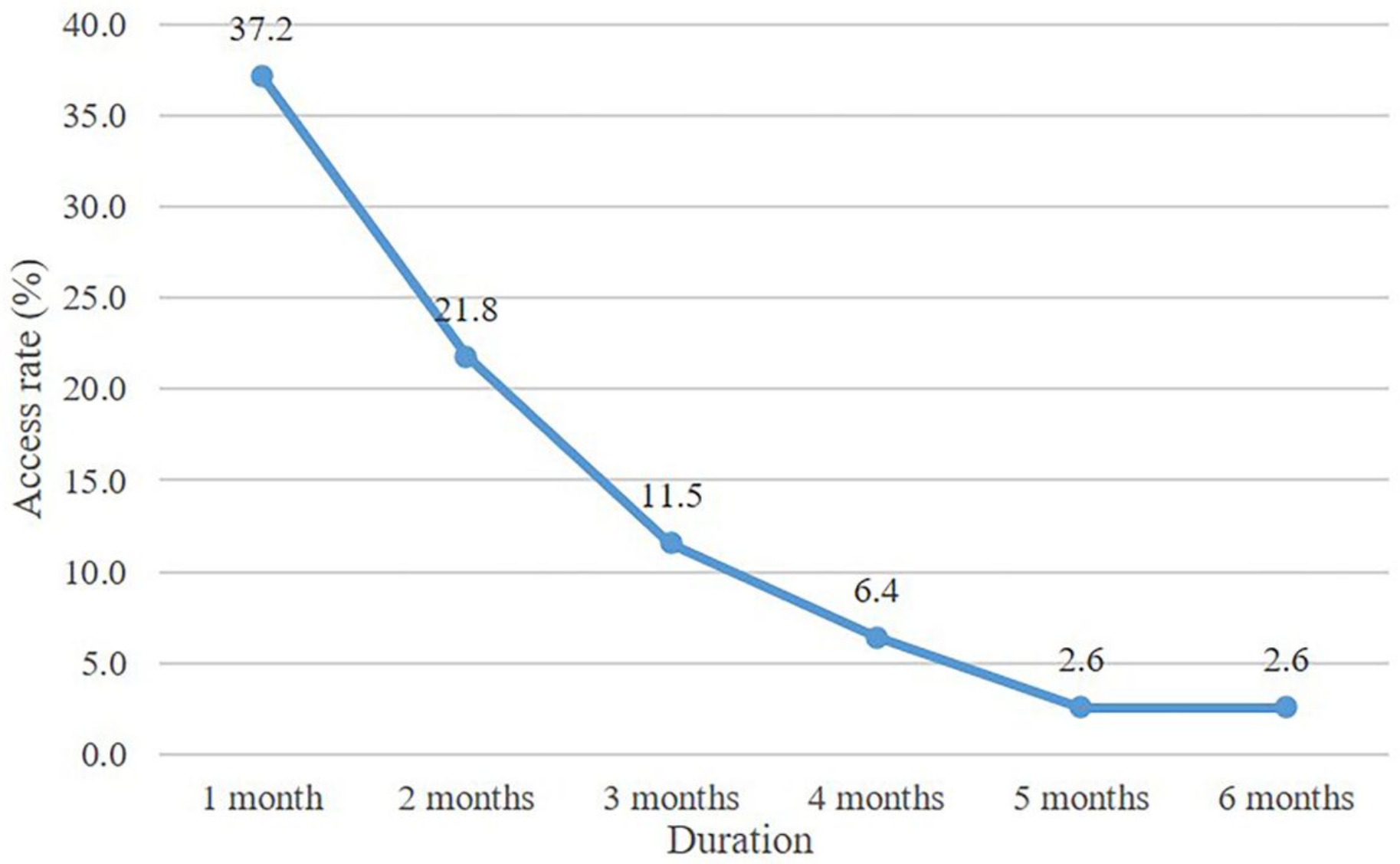

Figure 2

The access rate to PharmQuit in the intervention group within the 6 month follow-up $(n=78)$

\section{Supplementary Files}

This is a list of supplementary files associated with this preprint. Click to download.

- Additionalfile1CONSORT2010ChecklistAsayutetal.doc

- Additionalfile1CONSORT2010ChecklistAsayutetal.doc

- Additionalfile2Asayutetal.docx

- Additionalfile2Asayutetal.docx 